\title{
Determining clinical and biological indicators for health outcomes in adult patients with childhood onset of congenital adrenal hyperplasia
}

\author{
Anne Bachelot 1,2, Jean Louis Golmard 2,3, Jérôme Dulon', Nora Dahmoune', \\ Monique Leban ${ }^{4}$, Claire Bouvattier ${ }^{5,6}$, Sylvie Cabrol ${ }^{2,7}$, Juliane Leger ${ }^{8,9}$, \\ Michel Polak ${ }^{10,11}$ and Philippe Touraine ${ }^{1,2}$
}

${ }^{1}$ Department of Endocrinology and Reproductive Medicine, Centre de Référence des Maladies Endocriniennes Rares de la Croissance, AP-HP, IE3M, Groupe Hospitalier Pitié-Salpêtrière, 47-83 Boulevard de l'Hôpital, 75013 Paris, France, ${ }^{2}$ UPMC Univ Paris 06, Paris, France, ${ }^{3}$ Clinical Research Unit, AP-HP, Hôpital Pitié-Salpêtrière, Paris, France, ${ }^{4}$ Department of Hormonal Biochemistry, AP-HP, Hôpital Pitié-Salpêtrière, Paris, France, ${ }^{5}$ Pediatric Endocrinology, AP-HP, Hôpital Bicêtre, Le Kremlin Bicêtre, France, ${ }^{6}$ Faculté de Médecine Paris-Sud, Université Paris-Sud 11, Le Kremlin-Bicêtre F-94276, France, ${ }^{7}$ Pediatric Endocrinology, AP-HP, Hôpital Trousseau, Paris, France, ${ }^{8}$ Pediatric Endocrinology, AP-HP, Hôpital Robert Debré, Paris, France, ${ }^{9}$ Université Paris Diderot Paris 07, Paris, France,

${ }^{10}$ Pediatric Endocrinology, AP-HP, Hôpital Necker Enfants-Malades, Paris, France and ${ }^{11}$ Université Paris Descartes Paris 05, Paris, France

\author{
Correspondence \\ should be addressed \\ to $P$ Touraine \\ Email \\ philippe.touraine@psl.aphp.fr
}

\begin{abstract}
Aim: Adverse outcomes in adult congenital adrenal hyperplasia (CAH) patients are frequent. The determinants of them have not yet been established.

Objective: To establish the prevalence of adverse outcomes and to find determining factors for each of them.

Design, patients, and methods: Cross-sectional monocentric study of 104 patients with childhood onset of CAH (71 women, 33 men). Analysis established first the determinants of clinical, hormonal, genetic variables and second a composite criterion for some of the outcomes and determinants.

Results: BMI was above $25 \mathrm{~kg} / \mathrm{m}^{2}$ in $44 \%$ of the cohort, adrenal hyperplasia and/or nodules were present in $45 \%$ of the patients, and irregular menstrual cycles and hyperandrogenism were found in 50 and $35 \%$ of the women respectively. In univariate analysis, the determinants of these outcomes were all linked to disease control, especially 17-hydroxyprogesterone (17OHP) and androstenedione concentrations. Low weight was a determinant of abnormal bone mineral density (BMD) ( $60 \%$ of the cohort). Multivariate analysis confirmed these data. A classic form (CF) of CAH was a determinant of testicular adrenal rest tumors (TARTs) (36\% of the men). Total cumulative glucocorticoid dose was a determinant of BMI and TART, whereas fludrocortisone dose was a determinant of TART $(P=0.03)$. In men, the composite criterion was associated with androstenedione concentration and CF. In women, the composite criterion was associated with total testosterone concentration.

Conclusion: The present study confirms the high prevalence of adverse outcomes in CAH patients. These are, most often, related to disease control. The impaired health status of adults with $\mathrm{CAH}$ could therefore be improved through the modification of treatment.

European Journal of

Endocrinology

(2015) 173, 175-184
\end{abstract}

(C) 2015 European Society of Endocrinology Printed in Great Britain
Published by Bioscientifica Ltd 


\section{Introduction}

Twenty-one-hydroxylase deficiency (21OHD) is the most common form of congenital adrenal hyperplasia (CAH) $(1,2)$. CAH is classified according to symptoms, age of presentation, and genetics, and it is usually divided into two forms: classic, or severe, form (CF) and non-classic form (NCF). Improvement of CAH diagnosis and treatment in childhood has raised the question of adult health and care. Replacing steroid deficiency and avoiding the long-term consequences of $\mathrm{CAH}$ and glucocorticoid use are the aims of the current medical treatment. Studies have shown the presence of adverse outcomes in adult CAH patients $(3,4)$. In a prospective cross-sectional study conducted in the United Kingdom in 203 patients, BMI was found to be higher than that in the health survey for England data, and osteopenia (40\%) and osteoporosis (7\%) were common (5). In an American cross-sectional study in $244 \mathrm{CAH}$ patients (183 CF, $61 \mathrm{NCF}$ ) who were included in a natural history study by the National Institutes of Health, obesity was present in approximately one-third of patients across phenotypes, and $37 \%$ of adults had low bone mineral density (BMD) (6). Hirsutism was common (32\% CF, 59\% NCF). Testicular adrenal rest tumors (TARTs) were found in CF males (33\% of boys, $44 \%$ of men). Adrenal morphology has not been precisely studied, but some data suggest that $\mathrm{CAH}$ patients exhibit an increased incidence of adrenal hyperplasia and tumors $(7,8,9,10)$.

Taken together, these studies suggest that adult patients with $\mathrm{CAH}$ have a higher morbidity than that of the general population. However, these complications do not concern all adult CAH patients. Roles for glucocorticoid treatment and the severity of the genotype have been proposed. Recently, Krone et al. (11) analyzed the correlation between the genotype and treatment and health status in 153 adult patients. They found no associations between genotype and clinical parameters in this genotype/phenotype analysis. Nevertheless, the determining factors of the adverse outcomes have never been studied and should be elucidated in order to prevent their onset. In this context, the aims of the present study were to describe the adverse outcomes in a large monocentric cohort of adult CAH patients and to find the determinants of each of them. To perform the study, two different analyses were constructed: the first analysis involved a search for the determinants of each health status criterion (namely, BMI of $>25 \mathrm{~kg} / \mathrm{m}^{2}$, BMD, CT scan for both sexes, the presence of TARTs for men and regular menstrual cycles and hyperandrogenism for women) among genotype, clinical history, and treatment of the disease; the second analysis synthesized the correlated health status criteria in one composite criterion for each sex and assessed the determinants of that criterion.

\section{Subjects and methods}

\section{General procedures}

We conducted a cross-sectional monocentric study among all of the consecutive CAH patients followed-up in our referral center between January 2003 and June 2013. Diagnosis was confirmed by genetic analysis in all of the patients. Inclusion criteria were: adulthood ( $>16$ years old); the presence of $\mathrm{CF}$ or NCF CAH diagnosed during childhood ( $<10$ years old) according to the predicted severity of the mutations; and the availability of complete patient files, including clinical examination, BMD measurements, CT scan, testicular ultrasonography for men, and biological and hormonal evaluation, all of which must have been performed within a 1-month period.

The health status of adult CAH patients was defined by the following criteria. BMI was calculated as weight $/$ height $^{2}\left(\mathrm{~kg} / \mathrm{m}^{2}\right)$, and patients were divided into two categories: normal weight of $\leq 25 \mathrm{~kg} / \mathrm{m}^{2}$ or overweight/obese. BMD was measured at the lumbar and femoral levels, and patients were divided into two categories: normal or osteopenia/osteoporosis, according to the WHO criteria (12). Adrenal morphology on CT scan was divided into two categories: normal or the presence of adrenal hyperplasia (defined by an arm thickness of more than $5 \mathrm{~mm}$ ) (13) or adenomas. In women, the regularity of menses was evaluated before the beginning of any therapy known to interfere with the menstrual cycle and was divided into two categories: regular ( $28 \pm 2$ days) or oligomenorrhea/amenorrhea. Finally, clinical hyperandrogenism was defined by the presence of hirsutism (a score of $>8$ in the modified Ferriman Gallwey scale) (14), acne, and/or alopecia; in men, TARTs were detected by testicular ultrasonography.

To determine the total cumulative doses (TCDs) of glucocorticoid and mineralocorticoid, all daily treatment and annual heights and weights were noted for each patient from day 1 of the diagnosis to the day of clinical, hormonal, and anatomical evaluation based on both pediatric and adult files, as previously described (15). Doses of the various glucocorticoids were converted to growth-retarding cortisol equivalents ( $1 \mathrm{mg}$ of dexamethasone $=16 \mathrm{mg}$ of prednisone $=80 \mathrm{mg}$ of hydrocortisone) 
$(15,16,17)$. Each year, we summed every daily dose of treatment and divided the total by the corresponding body area to obtain the annual cumulative doses of hydrocortisone $\left(\mathrm{mg} / \mathrm{m}^{2}\right.$ per year). Each patient's TCD $\left(\mathrm{mg} / \mathrm{m}^{2}\right)$ was obtained by adding together these annual cumulative doses. Average daily hydrocortisone treatments $\left(\mathrm{mg} / \mathrm{m}^{2}\right.$ per day) were determined every year.

Blood samples for the measurement of insulin, glucose, total cholesterol, triglycerides, HDL and LDL cholesterol concentrations, plasma 17-hydroxyprogesterone (17OHP), total testosterone, androstenedione, progesterone, estradiol, estrone, adrenocorticotropin (ACTH), and renin were taken at $0800 \mathrm{~h}$ after an overnight fast. Steroid medications were taken before the blood tests.

\section{Search for the determinants of the different health status criteria}

The first analysis involved an assessment of the relationships between each health status criterion and clinical variables: age at diagnosis; age at start of puberty (Tanner stage G2); clinical form of CAH (CF or NCF); time since $\mathrm{CAH}$ diagnosis (years); Prader stage and age at menarche in women; weight, height, waist, and hip circumference; daily dose of hydrocortisone and fludrocortisone; genetic form of $\mathrm{CAH}$ (group 0, null mutation; group A, homozygous for IVS2 splice mutation or compound heterozygous for IVS2 and null mutations; group B, homozygous or compound heterozygous for I172N mutation or similar severity; group $\mathrm{C}$, homozygous or compound heterozygous for a non-severe mutation, mainly V281L or P30L); and the biological variables estradiol, follicle-stimulating hormone (FSH), luteinizing hormone (LH), total testosterone, sex hormone-binding globulin (SHBG), 17OHP, progesterone, renin, ACTH, androstenedione, insulin, glycemia, and homeostatic model assessment (HOMA) index.

We sought to synthesize the health status criteria in one composite criterion. The second analysis therefore synthesized the correlated criteria into one composite criterion. A composite criterion was determined for each sex from the phi coefficients. The determinants of each composite criterion were then assessed.

\section{Assays}

Serum and plasma samples were stored at $-20^{\circ} \mathrm{C}$ until analysis. Serum FSH, LH, estradiol, progesterone, total testosterone, SHBG, and dehydroepiandrosterone sulfate were measured by the Modular E170 automated chemiluminescent immunometric method (Roche Diagnostics) with an intra-assay coefficient of variation (CV) of $<3.3 \%$. Serum androstenedione was measured after extraction by RIA IM0674 (Immunotec, Marseille, France) with an intraassay CV of $<7.1 \%$. Commercial immunoassays were used to measure 17OHP (OHP-CT, Cis Bio International, Gif sur Yvette, France), renin (Radioimmunométrie renin Cisbio, Cis Bio International), and ACTH (immunoradiometric assay, Immunotech Beckmann Coulter). Insulin was measured by an immunoradiometric assay according to the manufacturer's protocol (Bi Insulin IRMA, Cis Bio International, Marseille, France).

\section{BMD assessment}

Femoral neck and lumbar spine BMD were assessed by a Hologic Densitometer QDR 1000 (Hologic, Roissy, France). BMD results at the femoral neck and lumbar spine L2-L4 were evaluated and expressed as absolute values in $\mathrm{g} / \mathrm{cm}^{2}$ and $T$-scores ((BMD - peak bone mass)/s.D.). OFELY Caucasian reference curves were used to calculate the $T$-scores for the women (18), and Hologic's TK91 norms were applied for the men. We were able to use $T$-scores to interpret and compare the results because all of the patients were $<40$ years old, and the general population's peak bone mass does not decrease at this age (18). According to the World Health Organization criteria, osteoporosis was defined as a $T$-score of $<-2.5$ s.D., and osteopenia was defined as a $T$-score between -2.5 and -1 s.D. Normal bones had a BMD T-score of -1 s.D. or higher (12).

\section{Testicular sonography}

Grayscale and color Doppler ultrasonography were obtained in the longitudinal and transverse planes by using an anterior approach. All ultrasonographic examinations were performed by a staff radiologist with experience in scrotal ultrasound.

\section{Adrenal CT scan}

Patients underwent computed tomography imaging of the adrenal glands. The size of the adrenal glands was evaluated, and the glands were classified as normal or hyperplasia (arm thickness of more than $5 \mathrm{~mm}$ ). If adrenal nodules were present, their sizes were measured, and attenuation measurements were obtained.

\section{Statistical analysis}

Descriptive statistics used numbers and percentages for qualitative variables and means \pm s.D. for quantitative 
ones. For the first analysis, the same statistical method was used for each health status criterion. First, a univariate analysis was performed using $\chi^{2}$ or Fisher's exact tests for qualitative variables and two-sample Wilcoxon's tests for quantitative ones. In the second step, a stepwise logistic regression was performed. Potential covariates included in the regression were the ones that were found to be significant with a $P$ value of $<0.10$ in the univariate analysis, and the covariates retained in the final model were found to be significant with a $P$ value $<0.05$ by the Wald test. The second analysis involved two quantitative composite criteria, and it was divided into a composite criterion definition step, followed by a univariate analysis and a multivariate analysis. The composite criteria were determined from the associations between simple criteria, as measured by phi coefficients (phi coefficients are a measure of the association between qualitative variables, and they are numerically equal to Pearson correlation coefficients when the qualitative variables are coded as 0 or 1). Finally, the criteria were defined as the number of abnormal values of a subset of simple criteria that were all pairwise positively correlated. The univariate analysis was performed using $\chi^{2}$ and Fisher's exact tests for qualitative variables and Spearman's rank correlation coefficient tests for quantitative variables. The multivariate analysis used a stepwise multiple linear regression. Covariates that were linked to the criteria with a univariate $P$ value of $<0.10$ were entered into the stepwise regression, and covariates with a $P$ value of $<0.05$ were retained in the final models. All tests were two-sided, and a $P$ value of $<0.05$ was considered significant. Computations were performed using SAS V9 statistical package (SAS Institute, Cary, NC, USA).

\section{Results}

\section{Population}

One hundred four patients fulfilled the inclusion criteria, including 71 women and 33 men. The mean age was 27.9 years (range 16-52) at the time of the inclusion. Fifty-three (30 females, 23 males) had the salt wasting (SW) form of CAH. Seventeen patients (15 females, two males) were diagnosed as classical simple virilizing (SV) patients. In the remaining 34 patients ( 26 females, eight males), NCF CAH was diagnosed during childhood, between the ages of 1 and 10 years, because of premature adrenarche. The mean time since diagnosis was 25 years (range 9-52). Ninetyfour patients were on hydrocortisone, ten patients were on dexamethasone, and none were on prednisone. The age at diagnosis and evaluation and the glucocorticoid doses for the males and females in each subgroup (CF and NCF) are presented in Table 1.

The prevalence of $\mathrm{CAH}$ adverse outcomes for each sex are represented in Fig. 1. In summary, BMI was $>25 \mathrm{~kg} / \mathrm{m}^{2}$ in $44 \%$ of the patients ( $53 \%$ of women, $40 \%$ of men; mean BMI $24.9 \mathrm{~kg} / \mathrm{m}^{2}$, range 17.9-45.6). Eighty-seven patients underwent BMD assessment. BMD was found to be abnormal in $60 \%$ of them ( $50 \%$ of women, $79 \%$ of men). Seventy-six patients had an adrenal CT scan. Adrenal hyperplasia was found in $45 \%$ of the patients, and adrenal adenomas were found in $25 \%$ of them. Among the 71 women, 50\% had irregular menstrual cycles, and 35\% had hyperandrogenism. TARTs were found by testicular ultrasonography in $36 \%$ of the 33 men.

\section{Univariate analysis}

The determinants of the health status criteria BMI, CT scan, and BMD are presented in Table 2 . The determinants of higher BMI were the time since diagnosis and renin, androstenedione, 17OHP, and LH concentrations. The determinants of abnormal BMD were weight $(67 \pm 11$ vs $62 \pm 13 \mathrm{~kg}, P=0.02)$. The determinants of abnormal CT scan were renin, androstenedione, ACTH, 17OHP, and progesterone concentrations. In women, the presence of hyperandrogenism or irregular menstrual cycles was also related to the hormonal control of $\mathrm{CAH}$, including $17 \mathrm{OHP}$, androstenedione, or ACTH concentrations

Table 1 Ages at diagnosis and evaluation and steroid doses for males and females in each subgroup (classic and non-classic).

\begin{tabular}{|c|c|c|c|c|c|}
\hline Sex & Form of CAH & Age at diagnosis (days) & $\begin{array}{c}\text { Age at evaluation } \\
\text { (years) }\end{array}$ & $\begin{array}{l}\text { TCD of glucocorticoid } \\
\qquad\left(\mathrm{g} / \mathrm{m}^{2}\right)\end{array}$ & $\begin{array}{l}\text { TCD of mineralo- } \\
\text { corticoid }\left(\mathrm{mg} / \mathrm{m}^{2}\right)\end{array}$ \\
\hline Female & $\begin{array}{l}\text { Classic }(n=45) \\
\text { Non-classic }(n=26)\end{array}$ & $\begin{array}{r}409 \pm 1026 \\
2535 \pm 708^{\ddagger}\end{array}$ & $\begin{array}{l}30.9 \pm 8.1 \\
25.0 \pm 6.5^{\dagger}\end{array}$ & $\begin{array}{l}210 \pm 88 \\
69 \pm 61^{\ddagger}\end{array}$ & $\begin{array}{l}24 \pm 42 \\
0.2 \pm 0.2^{\ddagger}\end{array}$ \\
\hline Male & $\begin{array}{l}\text { Classic }(n=25) \\
\text { Non-classic }(n=8)\end{array}$ & $\begin{array}{c}201 \pm 646 \\
2334 \pm 1160^{\dagger \S}\end{array}$ & $\begin{array}{l}27.0 \pm 7.3 \\
22.0 \pm 7.6 *\end{array}$ & $\begin{array}{l}189 \pm 99 \\
49 \pm 21^{\dagger}\end{array}$ & $\begin{array}{c}22 \pm 38 \\
0.6 \pm 1.7^{\dagger}\end{array}$ \\
\hline
\end{tabular}

$\mathrm{CAH}$, congenital adrenal hyperplasia; TCD, total cumulative dose. ${ }^{\star} P<0.05,{ }^{\dagger} P<0.01,{ }^{\ddagger} P<0.001$ non-classic vs classic form in each sex. ${ }^{\S} P<0.05$ men vs women in each form of $\mathrm{CAH}$.

www.eje-online.org 


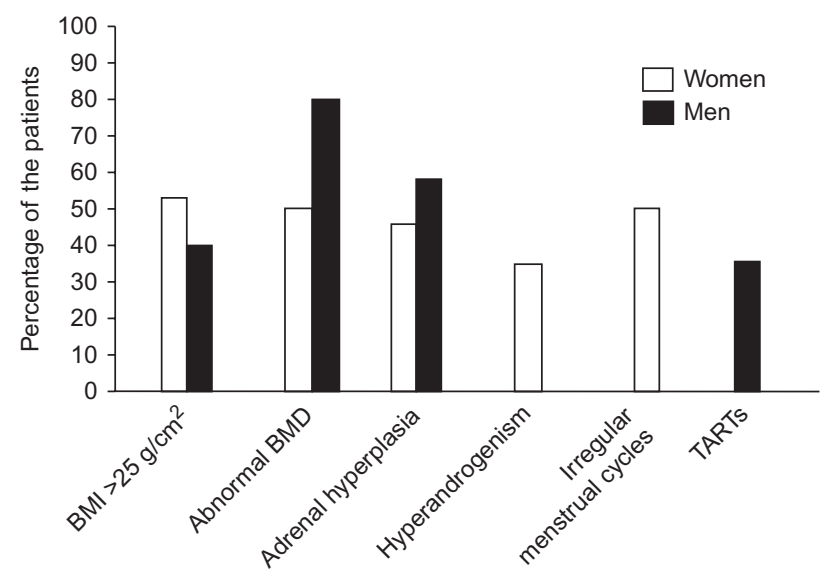

Figure 1

Prevalence of adverse outcomes in the adult $\mathrm{CAH}$ patients according to sex.

$(P<0.05$, Table 3$)$. Finally, the determinants of the presence of adrenal rest tumors in men were the time since diagnosis $(21.2 \pm 9.0$ vs $28.4 \pm 5.7$ years, $P=0.02)$ and the genetic form of the disease (i.e., the presence of $\mathrm{CF}$ CAH) $(P=0.002$, Table 3$)$.

TCDs of glucocorticoid and fludrocortisone were calculated in 71 patients (Table 1). Annual daily hydrocortisone doses from birth to 25 years old are represented in Fig. 2. A comparison of CAH patients with or without calculated TCD is presented in Table 4. There were no differences between the two groups regarding the prevalence of comorbidities, but patients with calculated TCD were significantly younger. Among the 71 patients with calculated TCD, we identified that 26 patients had received dexamethasone during their lifetime. TCD of glucocorticoid was $201 \pm 92 \mathrm{~g} / \mathrm{m}^{2}$ in patients with CF CAH and $62 \pm 51 \mathrm{~g} / \mathrm{m}^{2}$ in patients with NCF CAH. TCD of fludrocortisone was $23 \pm 40 \mathrm{mg} / \mathrm{m}^{2}$ in patients with $\mathrm{CF}$ CAH and $0.4 \pm 1 \mathrm{mg} / \mathrm{m}^{2}$ in patients with NCF CAH. TCD of glucocorticoid before 18 years was calculated to represent pediatric doses of HC. Pediatric TCD dose was $123 \pm$ $57 \mathrm{~g} / \mathrm{m}^{2}$ in patients with CF CAH and $47 \pm 17 \mathrm{~g} / \mathrm{m}^{2}$ in patients with NCF CAH.

TCD of glucocorticoid was a determinant of BMI $\left(137 \pm 97\right.$ for patients with normal BMI vs $199 \pm 103 \mathrm{~g} / \mathrm{m}^{2}$ for patients with BMI of $>25 \mathrm{~kg} / \mathrm{m}^{2}, P=0.01$ ) and TART $\left(125.9 \pm 105.5 \mathrm{~g} / \mathrm{m}^{2}\right.$ for patients without TART and $199.3 \pm 95.6 \mathrm{~g} / \mathrm{m}^{2}$ for patients with TART, $\left.P=0.05\right)$. Pediatric TCD dose was a determinant of BMI $(74 \pm 49$ for patients with normal BMI vs $128 \pm 79 \mathrm{~g} / \mathrm{m}^{2}$ for patients with BMI of $>25 \mathrm{~kg} / \mathrm{m}^{2}, P=0.02$ ), abnormal adrenal CT scan $\left(88.7 \pm 54.8 \mathrm{~g} / \mathrm{m}^{2}\right.$ for patients with normal CT scan vs $120.5 \pm 61.0 \mathrm{~g} / \mathrm{m}^{2}$ for patients with abnormal CT scan, $P=0.03)$. TCD of fludrocortisone was found to be a determinant of the presence of TARTs $\left(8 \pm 14 \mathrm{mg} / \mathrm{m}^{2}\right.$ for patients without TART and $30 \pm 52 \mathrm{mg} / \mathrm{m}^{2}$ for patients with TART, $P=0.03)$.

\section{Multivariate analysis}

Multivariate analysis was performed in the whole population for BMI, BMD, and CT scan. The determinants of BMI of $>25 \mathrm{~kg} / \mathrm{m}^{2}$ were age (odds ratio $(\mathrm{OR})=1.074$ (1.013-1.139), $P=0.01)$ and androstenedione concentration $(\mathrm{OR}=1.152(1.051-1.262), P<0.001)$. Concerning

Table 2 Univariate analysis of the health status criteria BMI, BMD, and CT scan in the entire population, $n=104$. Means \pm s.D.

\begin{tabular}{|c|c|c|c|c|c|c|c|c|c|}
\hline & \multicolumn{3}{|c|}{ BMI $^{\mathbf{a}}$} & \multicolumn{3}{|c|}{ BMD $^{b}$} & \multicolumn{3}{|c|}{ CT scan ${ }^{c}$} \\
\hline & $\begin{array}{c}\leq 25 \mathrm{~kg} / \mathrm{m}^{2} \\
n(\%)\end{array}$ & $\begin{array}{c}>25 \mathrm{~kg} / \mathrm{m}^{2} \\
n(\%)\end{array}$ & $P$ & $\begin{array}{l}\text { Normal } \\
n(\%)\end{array}$ & $\begin{array}{c}\text { Abnormal } \\
n(\%)\end{array}$ & $P$ & $\begin{array}{l}\text { Normal } \\
n(\%)\end{array}$ & $\begin{array}{c}\text { Abnormal } \\
n(\%)\end{array}$ & $P$ \\
\hline Number of patients & $58(56 \%)$ & $46(44 \%)$ & & 35 & 52 & & 34 & 42 & \\
\hline Age (years) & $26.6 \pm 7.1$ & $29.9 \pm 8.6$ & 0.05 & $27.6 \pm 8.5$ & $27.5 \pm 7.8$ & NS & $27.6 \pm 8.8$ & $28.9 \pm 8.8$ & NS \\
\hline $\begin{array}{l}\text { Time since diagnosis } \\
\text { (years) }\end{array}$ & $23.4 \pm 8.9$ & $27.5 \pm 9.5$ & 0.03 & $24.5 \pm 10.4$ & $24.8 \pm 9.3$ & NS & $24.1 \pm 10.4$ & $27.1 \pm 8.8$ & NS \\
\hline Weight $(\mathrm{kg})$ & NA & NA & & $67 \pm 11$ & $62 \pm 13$ & 0.02 & $62 \pm 12$ & $68 \pm 14$ & NS \\
\hline $170 \mathrm{HP}(\mathrm{ng} / \mathrm{ml})$ & $45.5 \pm 114$ & $93.9 \pm 143$ & 0.02 & $82.8 \pm 142.7$ & $53.5 \pm 119.5$ & NS & $10.3 \pm 19.6$ & $102 \pm 149$ & $<0.001$ \\
\hline Androstenedione $(\mathrm{ng} / \mathrm{ml})$ & $3.1 \pm 3.2$ & $8.6 \pm 10.4$ & 0.01 & $7.3 \pm 10.6$ & $3.9 \pm 4.8$ & NS & $2.4 \pm 4.3$ & $8.1 \pm 8.6$ & $<0.001$ \\
\hline Progesterone (ng/ml) & $6.9 \pm 15.1$ & $11.9 \pm 18.9$ & NS & $10.4 \pm 19.1$ & $8.4 \pm 16.9$ & NS & $3.3 \pm 7.4$ & $12.7 \pm 18.7$ & 0.001 \\
\hline ACTH $(p g / m l)$ & $110 \pm 245$ & $138 \pm 193$ & NS & $128 \pm 187$ & $128 \pm 260$ & NS & $43 \pm 87$ & $189 \pm 264$ & 0.003 \\
\hline $\operatorname{Renin}(\mathrm{pg} / \mathrm{ml})$ & $19.8 \pm 14.8$ & $58.8 \pm 12.6$ & 0.03 & $63.2 \pm 144.1$ & $23.3 \pm 21.8$ & NS & $16.5 \pm 13.5$ & $40.7 \pm 56.9$ & 0.01 \\
\hline
\end{tabular}

NA, not appropriate; NS, nonsignificant.

a BMI was divided into two categories: normal weight $\leq 25 \mathrm{~kg} / \mathrm{m}^{2}$ or overweight/obese.

bBMD was divided into two categories according to the WHO criteria: normal or osteopenia/osteoporosis.

${ }^{c} \mathrm{CT}$ scan was divided into two categories: normal or presence of adrenal hyperplasia (defined by an arm thickness of more than $5 \mathrm{~mm}$ ) or adenomas. 
Table 3 Univariate analysis of hyperandrogenism and menstrual cycles in women $(n=71)$ and TARTs in men ( $n=33)$. Means \pm s.D.

\begin{tabular}{l}
\hline \\
\\
\hline Number of patients \\
$17 \mathrm{OHP}(\mathrm{ng} / \mathrm{ml})$ \\
Total testosterone \\
(ng/ml) \\
Androstenedione \\
(ng/ml) \\
Estradiol (pg/ml) \\
ACTH $(\mathrm{pg} / \mathrm{ml})$ \\
\hline
\end{tabular}

\begin{tabular}{|c|c|c|}
\hline \multicolumn{3}{|c|}{ Hyperandrogenism $^{a}$} \\
\hline $\begin{array}{c}\text { Absent } \\
n(\%)\end{array}$ & $\begin{array}{c}\text { Present } \\
n(\%)\end{array}$ & $P$ \\
\hline $45(65 \%)$ & $24(35 \%)$ & \\
\hline $21 \pm 37$ & $168 \pm 212$ & 0.004 \\
\hline $0.5 \pm 0.7$ & $1.9 \pm 2.3$ & 0.001 \\
\hline $2.8 \pm 4.5$ & $10.1 \pm 11.9$ & 0.003 \\
\hline $94 \pm 80$ & $33 \pm 18$ & 0.001 \\
\hline $69 \pm 159$ & $194 \pm 261$ & 0.003 \\
\hline
\end{tabular}

\begin{tabular}{|c|c|c|}
\hline \multicolumn{3}{|c|}{ Regular menstrual cycles ${ }^{b}$} \\
\hline $\begin{array}{c}\text { Yes } \\
n(\%)\end{array}$ & $\begin{array}{c}\text { No } \\
n(\%)\end{array}$ & $P$ \\
\hline $35(50 \%)$ & $35(50 \%)$ & \\
\hline $16 \pm 34$ & $135 \pm 191$ & 0.003 \\
\hline $0.49 \pm 0.78$ & $1.61 \pm 2.05$ & 0.003 \\
\hline $2.8 \pm 4.7$ & $8.3 \pm 10.7$ & 0.009 \\
\hline $79 \pm 77$ & $65 \pm 64$ & NS \\
\hline $67 \pm 168$ & $157 \pm 232$ & 0.01 \\
\hline
\end{tabular}

\begin{tabular}{|c|c|c|}
\hline \multicolumn{3}{|c|}{ TARTs } \\
\hline $\begin{array}{c}\text { Absent } \\
n(\%)\end{array}$ & $\begin{array}{c}\text { Present } \\
n(\%)\end{array}$ & $P$ \\
\hline 21 (64\%) & $12(36 \%)$ & \\
\hline $42.5 \pm 76.2$ & $79.2 \pm 108.2$ & NS \\
\hline $5.0 \pm 1.9$ & $4.4 \pm 2.6$ & NS \\
\hline $4.4 \pm 4.9$ & $8.6 \pm 8.1$ & NS \\
\hline $26 \pm 12$ & $25 \pm 11$ & NS \\
\hline $70 \pm 104$ & $278 \pm 363$ & NS \\
\hline
\end{tabular}

NS, nonsignificant.

${ }^{a}$ Hyperandrogenism was defined by the presence of hirsutism, acne, and/or alopecia.

${ }^{\mathrm{b}}$ Regularity of menses was divided into two categories: regular or oligomenorrhea/amenorrhea.

the presence of abnormal BMD, the only significant determining factor was weight $(\mathrm{OR}=0.966(0.932-$ 1.001), $P=0.05)$, and for abnormal adrenal CT scan, the only determining factor was androstenedione concentration $(\mathrm{OR}=1.142(1.048-1.245), P=0.002)$. In women, a determinant of irregular menstrual cycles was $17 \mathrm{OHP}$ concentration $(\mathrm{OR}=1.014$ (1.003-1.026), $P=0.01)$, and for the presence of hyperandrogenism, the determinants were 17OHP $(\mathrm{OR}=1.022(1.005-1.039), P=0.01)$ and estradiol concentrations $(\mathrm{OR}=0.951 \quad(0.915-0.988)$, $P=0.01$ ). Multivariate analysis could not be performed in men because of the low sample size.

\section{Composite criteria}

All criteria were positively correlated, apart from the BMD measurement, which was negatively correlated with the others. We therefore synthesized all of correlated criteria into one composite criterion. A composite criterion was determined for each sex from the phi coefficients (data not shown). Thus, the composite criterion was defined as the total number of the following positively correlated events: in men: BMI of $>25 \mathrm{~kg} / \mathrm{m}^{2}$, the presence of TARTs, and the presence of an abnormal adrenal CT scan; in women: BMI of $>25 \mathrm{~kg} / \mathrm{m}^{2}$, the presence of irregular menstrual cycles, and hyperandrogenism.

Twenty-six men were included in the analysis. The factors that were positively correlated with the composite criterion were cumulative hydrocortisone dose per surface ( $r=0.39, P=0.0375)$, age at puberty $(r=-0.65, P=0.004)$, androstenedione $(r=0.52, P=0.0064)$, renin $(r=0.51$, $P=0.0073)$, and 170HP concentrations $(r=0.47$, $P=0.0153)$. Clinical form was close but not statistically significant (CF $0.5 \pm 0.8$ vs NCF $1.7 \pm 1.2, P=0.06$ ).
The independent factors found by multiple regression analysis were androstenedione concentration (partial $\left.r^{2}=0.18, P=0.0276\right)$ and clinical form of $\mathrm{CAH}$ (CF vs NCF, partial $r^{2}=0.1579, P=0.0392$ ).

Fifty women were included in the analysis. The quantitative factors that were positively correlated with the composite criterion were age at puberty $(r=-0.47$, $P=0.0115)$, androstenedione $(r=0.50, P=0.0004)$, renin $(r=0.38, P=0.0098), 17 \mathrm{OHP}(r=0.52, P=0.0001)$, testosterone $(r=0.50, P=0.0002)$, and progesterone concentrations ( $r=0.48, P=0.0011)$. No qualitative factors were associated with the composite criterion. Using multiple linear regression analysis, only one factor was found to be significant: total testosterone concentrations $\left(r^{2}=0.28\right.$, $P=0.0004)$. Similar results were obtained when considering only patients with CF CAH.

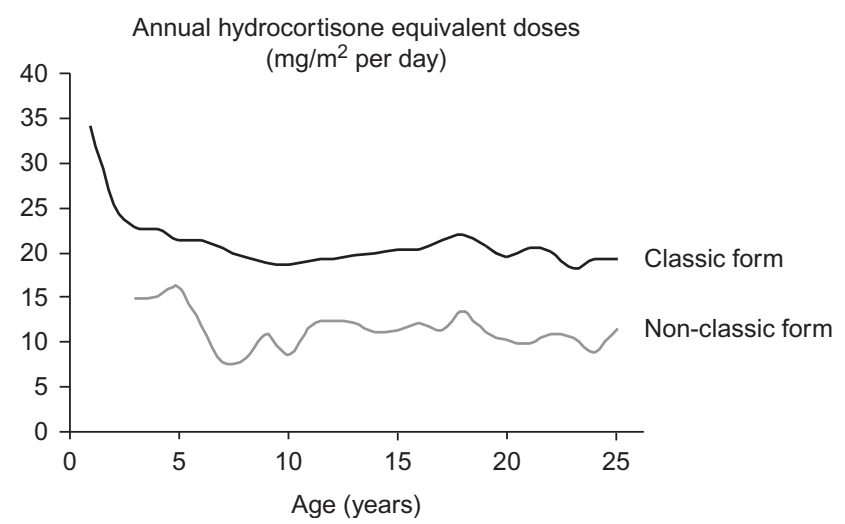

Figure 2

Annual average daily hydrocortisone equivalent doses from birth to 25 years old. 
Table 4 Comparison of clinical data and prevalence of comorbidities in the 71 CAH patients with calculated TCD and the remaining patients of the cohort.

\begin{tabular}{|c|c|c|c|}
\hline & $\begin{array}{l}\text { Patients with } \\
\text { calculated TCD } \\
\quad(n=71)\end{array}$ & $\begin{array}{c}\text { Patients } \\
\text { without } \\
\text { calculated TCD } \\
(n=33)\end{array}$ & $P$ value \\
\hline $\begin{array}{l}\text { Age at diagnosis } \\
\text { (days) }\end{array}$ & $948 \pm 1277$ & $1158 \pm 1460$ & NS \\
\hline $\begin{array}{l}\text { Age at evaluation } \\
\text { (years) }\end{array}$ & $26 \pm 7.5$ & $31 \pm 8.2$ & 0.04 \\
\hline $\mathrm{NCF} / \mathrm{CF}$ & $29 \%$ & $32 \%$ & NS \\
\hline $\mathrm{BMI}>25 \mathrm{~kg} / \mathrm{m}^{2}$ & $44 \%$ & $43 \%$ & NS \\
\hline Abnormal BMD & $58 \%$ & $64 \%$ & NS \\
\hline Abnormal CT scan & $42 \%$ & $33 \%$ & NS \\
\hline $\begin{array}{l}\text { Irregular menstrual } \\
\text { cycles }\end{array}$ & $51 \%$ & $47 \%$ & NS \\
\hline Hyperandrogenism & $41 \%$ & $25 \%$ & NS \\
\hline TART & $13 \%$ & $7 \%$ & NS \\
\hline
\end{tabular}

TCD, total cumulative dose; NCF, non-classic form; CF, classic form; TART, testicular adrenal rest tumors; NS, nonsignificant.

\section{Discussion}

The present study was designed to highlight the determinants of adverse events in a single cohort of adult patients with childhood onset of CAH. Overweight and obesity were frequently observed (44\%), as were abnormal BMD (60\%), irregular menstrual cycles (50\%), hirsutism (35\%), and TARTs (36\%). These results are in accordance with previous results from other adult cohorts $(5,6)$. We were also interested in adrenal morphology, which had not been studied previously, and we found that adrenal hyperplasia and/or nodules were frequent (45\%). We identified determining factors for all of these health outcomes.

The prevalence of obesity and overweight in the present $\mathrm{CAH}$ patients is similar to that found in the latest nationwide survey (19). Obesity is estimated to be found in $15 \%$ of the French adult population: $15.7 \%$ of adult women and $14.3 \%$ of adult men. Overweight is estimated to be found in $32 \%$ (26.3\% of women, $38.8 \%$ of men). In the present study, obesity was present in $15 \%$ of the patients and overweight in $29 \%$. The determinants of overweight and obesity in the present $\mathrm{CAH}$ patients were age and hormonal control of the disease, that is, patients with the highest BMI had less hormonal control, based on renin, androstenedione, and 17OHP concentrations. TCD was also found to be a determining factor of high BMI, especially pediatric TCD. It should be noted that our patients were most likely treated with higher steroid doses during early life than the amounts that are recommended nowadays. It has been previously demonstrated that early rebound of BMI is associated with obesity in late childhood (19). This has been shown to be linked with hydrocortisone dosage and parental BMI (20). These findings reinforce the need to carefully monitor these patients from childhood, seeing as increased BMI in adults has been associated with increased fat mass and the presence of abdominal obesity, which represent important predictive factors of cardiovascular disease $(4,20,21,22$, $23,24,25,26,27)$.

We confirmed the results from our previous study on the high prevalence of BMD alteration in this population, especially in men $(4,15)$. We did not have a control population, but we used OFELY Caucasian reference curves to calculate women $T$-scores (18), and Hologic's TK91 norms were applied for men. In fact, 60\% of the participants had bone demineralization according to the WHO criteria, which is superior to a Gaussian repartition, in which $16 \%$ of the general population is under -1 s.D. (15). We recently conducted a trial to establish the role of the glucocorticoid TCD on BMD (15). We established that there was a negative relationship between TCD and lumbar and femoral BMD. BMI also appeared to protect patients from bone loss. In the present study, increased weight was a protective factor for osteoporosis and osteopenia, but we were not able to find any association with TCDs of glucocorticoid, probably because of the large cohort studied.

In women, the present study showed the importance of hormonal control on the regularity of menstrual cycles and confirmed that $\mathrm{CAH}$ women do not necessarily present a disruption of the gonadotropic axis and anovulation as a result of early exposure to adrenal steroids, as we had previously shown (28). This is also in accordance with a study by Casteràs et al. (29) which showed low fecundity in classic CAH patients but normal fertility in patients with parental project and spontaneous pregnancy in patients with strict control of progesterone concentrations in the follicular phase of the menstrual cycle. In men, TARTs were the only event that could not be linked to hormonal control, but they were associated with the severity of the disease $(30,31,32)$. Indeed, TARTs were found only in patients with CF CAH. Nevertheless, a recent study highlighted the presence of TARTs in two patients with NCF CAH (33). This should be confirmed in the future by other groups, because none of our eight males with NCF exhibited TARTs. We also showed that total glucocorticoid dose of hydrocortisone and fludrocortisone were determinants of TARTs. It has been shown that TARTs express adrenal-specific enzymes and ACTH 
and angiotensin II receptors (34). This could be an expression of a more severe form of $\mathrm{CAH}$ or noncompliance (i.e., less compliant patients received higher doses of glucocorticoid but nonetheless retained poor disease control and developed TARTs), or it could suggest that the doses of glucocorticoid were adjusted according to the presence or absence of TARTs. We cannot exclude any of these hypotheses on the sole basis of the present results.

Few studies that evaluated adrenal morphology by CT scan exist in CAH patients $(7,8,9,10)$. One such study showed that among 26 patients (eight with the NCF, four with the SW, and 14 with the SV form), nodules were found in six of the 11 patients with poor hormonal control but not in the 15 patients with regular or good hormonal control. Adrenal nodules in these six patients demonstrated a considerable size reduction and even disappearance after adequate replacement therapy, which suggests that these nodules were ACTH-dependent (10). Another study reported a high incidence of adrenal masses, which were present in $82 \%$ of the patients (7). The present study in a larger cohort of adult patients confirms the high incidence of adrenal hyperplasia and/or nodules and clearly shows their hormonal dependence, because the determining factors of these anomalies were all linked to hormonal control (i.e., high ACTH concentrations). Pediatric TCD was found to be a determinant for abnormal CT scan, which highlights the importance of precocious good hormonal control for preventing adrenal hyperplasia development and subsequent difficulty with hormonal equilibration.

In the present study, we thus demonstrated that all of the undesirable outcomes observed in adult CAH patients, except for TARTs, were linked to disease control. In particular, hormonal parameters that are linked to disease control, especially 17OHP and androstenedione, were found to be determinants of these outcomes: their concentrations were found to be higher in patients with worse outcomes. Moreover, when using the composite criterion, which affects the health outcomes of the CAH patients, we showed that it too was linked to hormonal parameters: that is, patients with the worst hormonal control have the worst health outcome. Consequently, we identified a subgroup of patients who poorly responded to treatment in terms of disease control but still developed an adverse effect, such as obesity or osteoporosis. Recent studies conducted by Han et al. $(35,36)$ showed similar findings to those in the present study: they examined the impact of glucocorticoid treatment regimen on health outcomes. Their results suggest that increased glucocorticoid dose is associated with increased blood pressure but does not necessarily improve disease control. A possible explanation developed by that group was that the less compliant patients received higher doses of glucocorticoid but nevertheless retained poor disease control and had worse metabolic profiles as a consequence of intermittent high glucocorticoid doses. This should be evaluated further and more precisely. Another explanation could be the presence in some patients of particular glucocorticoid receptor polymorphisms, which have been shown to be associated with poor metabolic state in $\mathrm{CAH}$ patients (37). Another interesting finding is the demonstration that clinical form of CAH (CF vs NCF diagnosed in childhood) does not seem to be a determining factor of adverse outcomes if the patients have controlled disease. Overall, the present study and the CaHASE cohort study suggest that poor health outcomes in adults are closely related to their treatment rather than to the severity of the enzyme deficiency $(34,35)$. The long-term impact of these complications on bone, cardiovascular events, and mortality should be analyzed in a longitudinal way in this population. Indeed, a recent study showed an increased mortality in patients with $\mathrm{CAH}$, especially CAH resulting from adrenal crisis (38).

The present study has two major biases: first, missing data may be a limitation, seeing as not all of the patients had extensive data recording. The study of this cohort nevertheless took advantage of the monocentric design. Despite this bias, our cohort was large enough to give power to our results, especially in women. The reduced number of men was also observed in other cohorts $(6,11$, $34,35)$. The other bias is the genetic heterogeneity of the population. However, we found the same results when excluding NCF patients. Moreover, time since diagnosis was a determinant of some criteria in univariate analysis, but this association did not persist in multivariate analysis. These results are not applicable to NCF cases diagnosed in adulthood, which are treated beginning at a later age and are not systematically treated with glucocorticoids.

In conclusion, the present study confirms the high prevalence of adverse outcomes in adult $\mathrm{CAH}$ patients but especially underlines for the first time specific determinants of those outcomes, that is, the predominant role of hormonal control and treatment in the development of these outcomes in a large monocentric cohort. The evidence that subgroups of patients poorly responded to treatment in terms of disease control but still developed some adverse effects should be further studied. Poor hormonal control and adverse outcomes are common in $\mathrm{CAH}$, which necessitates new treatments. Osteoporosis and obesity prophylaxis and TART screening should begin 
during childhood. A longitudinal study is needed to precisely identify the natural history of these adverse outcomes and to confirm their risk factors. Controlled drug trials in adults with $\mathrm{CAH}$ should also be carried out in order to define the best therapeutic approaches in these patients.

\section{Declaration of interest}

The authors declare that there is no conflict of interest that could be perceived as prejudicing the impartiality of the research reported.

\section{Funding}

This work was supported by a grant from Association Surrénales.

\section{Author contribution statement}

A Bachelot designed the study, analyzed the data, and wrote parts of the manuscript. J L Golmard analyzed the data and performed all of the statistical analyses. J Dulon and N Dahmoune managed the database. M Leban performed the hormonal assessment. C Bouvattier, S Cabrol, $\mathrm{J}$ Leger, and $\mathrm{M}$ Polak included their patients and reviewed the manuscript. $P$ Touraine designed the study and reviewed the manuscript.

\section{Acknowledgements}

We thank Dr Catherine Cormier for helpful discussion

\section{References}

1 White PC \& Speiser PW. Congenital adrenal hyperplasia due to 21-hydroxylase deficiency. Endocrine Reviews 200021 245-291. (doi:10.1210/edrv.21.3.0398)

2 Merke DP \& Bornstein SR. Congenital adrenal hyperplasia. Lancet 2005 365 2125-2136. (doi:10.1016/S0140-6736(05)66736-0)

3 Ogilvie CM, Crouch NS, Rumsby G, Creighton SM, Liao LM \& Conway GS. Congenital adrenal hyperplasia in adults: a review of medical, surgical and psychological issues. Clinical Endocrinology 2006 64 2-11. (doi:10.1111/j.1365-2265.2005.02410.x)

4 Bachelot A, Plu-Bureau G, Thibaud E, Laborde K, Pinto G, Samara D, Nihoul-Fékété C, Kuttenn F, Polak M \& Touraine P. Long-term outcome of patients with congenital adrenal hyperplasia due to 21-hydroxylase deficiency. Hormone Research 200767 268-276. (doi:10.1159/ 000098017)

5 Arlt W, Willis DS, Wild SH, Krone N, Doherty EJ, Hahner S, Han TS Carroll PV, Conway GS, Rees DA et al. Health status of adults with congenital adrenal hyperplasia: a cohort study of 203 patients. Journal of Clinical Endocrinology and Metabolism 201095 5110-5121. (doi:10.1210/jc.2010-0917)

6 Finkielstain GP, Kim MS, Sinaii N, Nishitani M, Van Ryzin C, Hill SC, Reynolds JC, Hanna RM \& Merke DP. Clinical characteristics of a cohort of 244 patients with congenital adrenal hyperplasia. Journal of Clinical Endocrinology and Metabolism 201297 4429-4438. (doi:10.1210/jc. 2012-2102)

7 Jaresch S, Kornely E, Kley HK \& Schlaghecke R. Adrenal incidentaloma and patients with homozygous or heterozygous congenital adrenal hyperplasia. Journal of Clinical Endocrinology and Metabolism 199274 685-689. (doi:10.12010/jcem.74.3.1311000)

8 Reisch N, Scherr M, Flade L, Bidlingmaier M, Schwarz HP, MüllerLisse U, Reincke M, Quinkler M \& Beuschlein F. Total adrenal volume but not testicular adrenal rest tumor volume is associated with hormonal control in patients with 21-hydroxylase deficiency. Journal of Clinical Endocrinology and Metabolism 201095 2065-2072. (doi:10.1210/jc.2009-1929)

9 German-Mena E, Zibari GB \& Levine SN. Adrenal myelolipomas in patients with congenital adrenal hyperplasia: review of the literature and a case report. Endocrine Practice 201117 441-447. (doi:10.4158/ EP10340.RA)

10 Giacaglia LR, Mendonca BB, Madureira G, Melo KF, Suslik CA, Arnhold IJ \& Bachega TA. Adrenal nodules in patients with congenital adrenal hyperplasia due to 21-hydroxylase deficiency: regression after adequate hormonal control. Journal of Pediatric Endocrinology \& Metabolism 200114 415-419. (doi:10.1515/JPEM.2001.14.4.415)

11 Krone N, Rose IT, Willis DS, Hodson J, Wild SH, Doherty EJ, Hahner S, Parajes S, Stimson RH, Han TS et al. Genotype-phenotype correlation in 153 adult patients with congenital adrenal hyperplasia due to 21-hydroxylase deficiency: analysis of the United Kingdom Congenital adrenal Hyperplasia Adult Study Executive (CaHASE) cohort. Journal of Clinical Endocrinology and Metabolism 201398 E346-E354. (doi:10.1210/jc.2012-3343)

12 Cummings SR, Bates D \& Black DM. Clinical use of bone mineral densitometry: clinical applications. Journal of the American Medical Association 2002288 1889-1897. (doi:10.1001/jama.288.15.1889)

13 Vincent JM, Morrison ID, Armstrong P \& Reznek RH. The size of normal adrenal glands on computed tomography. Clinical Radiology 199449 453-455. (doi:10.1016/S0009-9260(05)81739-8)

14 Hatch R, Rosenfield RL, Kim MH \& Tredway D. Hirsutism: implications, etiology, and management. American Journal of Obstetrics and Gynecology $1981140815-830$

15 Chakhtoura Z, Bachelot A, Samara-Boustani D, Ruiz JC, Donadille B, Dulon J, Christin-Maître S, Bouvattier C, Raux-Demay MC, Bouchard P et al. Impact of total cumulative glucocorticoid dose on bone mineral density in patients with 21-hydroxylase deficiency. European Journal of Endocrinology/European Federation of Endocrine Societies 2008158 879-887. (doi:10.1530/EJE-07-0887)

16 Jääskeläinen J \& Voutilainen R. Bone mineral density in relation to glucocorticoid substitution therapy in adult patients with 21-hydroxylase deficiency. Clinical Endocrinology 199645 707-713.

17 King JA, Wisniewski AB, Bankowski BJ, Carson KA, Zacur HA \& Migeon CJ. Long-term corticosteroid replacement and bone mineral density in adult women with classical congenital adrenal hyperplasia. Journal of Clinical Endocrinology and Metabolism 20063 865-869. (doi:10.1210/jc.2005-0745)

18 Arlot ME, Sornay-Rendu E, Garnero P, Vey-Marty B \& Delmas PD. Apparent pre- and postmenopausal bone loss evaluated by DXA at different skeletal sites in women: the OFELY cohort. Journal of Bone and Mineral Research 199712 683-690. (doi:10.1359/jbmr.1997.12.4.683)

19 http://www.roche.fr/content/dam/corporate/roche fr/doc/ obepi_2012.pdf.

20 Cornean RE, Hindmarsh PC \& Brook CG. Obesity in 21-hydroxylase deficient patients. Archives of Disease in Childhood 199878 261-263. (doi:10.1136/adc.78.3.261)

21 Volkl TM, Simm D, Beier C \& Dorr HG. Obesity among children and adolescents with classic congenital adrenal hyperplasia due to 21-hydroxylase deficiency. Pediatrics 2006117 e98-105. (doi:10.1542/peds.2005-1005)

22 Falhammar H, Filipsson H, Holmdahl G, Janson PO, Nordenskjold A, Hagenfeldt $\mathrm{K} \&$ Thoren $\mathrm{M}$. Metabolic profile and body composition in adult women with congenital adrenal hyperplasia due to 21-hydroxylase deficiency. Journal of Clinical Endocrinology and Metabolism 200792 110-116. (doi:10.1210/jc.2006-1350) 
23 Stikkelbroeck NM, Oyen WJ, van der Wilt GJ, Hermus AR \& Otten BJ. Normal bone mineral density and lean body mass but increased fat mass in young adult patients with congenital adrenal hyperplasia. Journal of Clinical Endocrinology and Metabolism 200388 1036-1042. (doi:10.1210/jc.2002-021074)

24 Falhammar H, Filipsson H, Holmdahl G, Janson PO, Nordenskjold A, Hagenfeldt $\mathrm{K} \&$ Thoren M. Metabolic profile and body composition in adult women with congenital adrenal hyperplasia due to 21-hydroxylase deficiency. Journal of Clinical Endocrinology and Metabolism 200792 110-116. (doi:10.1210/jc.2006-1350)

25 Hagenfeldt K, Ritzen EM, Ringertz H, Helleday J \& Carlstrom K. Bone mass and body composition of adult women with congenital virilizing 21-hydroxylase deficiency after glucocorticoid treatment since infancy. European Journal of Endocrinology/European Federation of Endocrine Societies 2000143 667-671. (doi:10.1530/eje.0.1430667)

26 Cameron FJ, Kaymakci B, Byrt EA, Ebeling PR, Warne GL \& Wark JD. Bone mineral density and body composition in congenital adrenal hyperplasia. Journal of Clinical Endocrinology and Metabolism 199580 2238-2243. (doi:10.1210/jcem.80.7.7608286)

27 Mooij CF, Kroese JM, Claahsen-van der Grinten HL, Tack CJ \& Hermus AR. Unfavorable trends in cardiovascular and metabolic risk in pediatric and adult patients with congenital adrenal hyperplasia? Clinical Endocrinology 201073 137-146. (doi:10.1111/j.1365-2265. 2009.03690.x)

28 Bachelot A, Chakhtoura Z, Plu-Bureau G, Coudert M, Coussieu C, Badachi Y, Dulon J, Charbit B, Touraine P \& CAHLH Study Group. Influence of hormonal control on LH pulsatility and secretion in women with classical congenital adrenal hyperplasia. European Journal of Endocrinology/European Federation of Endocrine Societies 2012 167 499-505. (doi:10.1530/EJE-12-0454)

29 Casteràs A, De Silva P, Rumsby G \& Conway GS. Reassessing fecundity in women with classical congenital adrenal hyperplasia (CAH): normal pregnancy rate but reduced fertility rate. Clinical Endocrinology $2009 \mathbf{7 0}$ 833-837. (doi:10.1111/j.1365.2265.2009.03563.x)

30 Claahsen-van der Grinten HL, Otten BJ, Stikkelbroeck MM, Sweep FC \& Hermus AR. Testicular adrenal rest tumours in congenital adrenal hyperplasia. Best Practice \& Research. Clinical Endocrinology \& Metabolism 200923 209-220. (doi:10.1016/j.beem.2008.09.007)

31 Reisch N, Flade L, Scherr M, Rottenkolber M, Pedrosa Gil F, Bidlingmaier M, Wolff H, Schwarz HP, Quinkler M, Beuschlein F et al. High prevalence of reduced fecundity in men with congenital adrenal hyperplasia. Journal of Clinical Endocrinology and Metabolism 200994 1665-1670. (doi:10.1210/jc.2008-1414)

32 Reisch N, Rottenkolber M, Greifenstein A, Krone N, Schmidt H, Reincke M, Schwarz HP \& Beuschlein F. Testicular adrenal rest tumors develop independently of long-term disease control: a longitudinal analysis of 50 adult men with congenital adrenal hyperplasia due to classic 21-hydroxylase deficiency. Journal of Clinical Endocrinology and Metabolism 201398 E1820-E1826. (doi:10.1210/jc.2012-3181)

33 Falhammar H, Nyström HF, Ekström U, Granberg S, Wedell A \& Thorén M. Fertility, sexuality and testicular adrenal rest tumors in adult males with congenital adrenal hyperplasia. European Journal of Endocrinology/European Federation of Endocrine Societies 2012166 441-449. (doi:10.1530/EJE-11-0828)

34 Claahsen-van der Grinten HL, Otten BJ, Sweep FC, Span PN, Ross HA, Meuleman EJ \& Hermus AR. Testicular tumors in patients with congenital adrenal hyperplasia due to 21-hydroxylase deficiency show functional features of adrenocortical tissue. Journal of Clinical Endocrinology and Metabolism 200792 3674-3680. (doi:10.1210/jc. 2007-0337)

35 Han TS, Stimson RH, Rees DA, Krone N, Willis DS, Conway GS, Arlt W, Walker BR, Ross RJ \& United Kingdom Congenital adrenal Hyperplasia Adult Study Executive (CaHASE) . Glucocorticoid treatment regimen and health outcomes in adults with congenital adrenal hyperplasia. Clinical Endocrinology 201378 197-203. (doi:10.1111/ cen.12045)

36 Han TS, Krone N, Willis DS, Conway GS, Hahner S, Rees DA, Stimson RH, Walker BR, Arlt W, Ross RJ et al. Quality of life in adults with congenital adrenal hyperplasia relates to glucocorticoid treatment, adiposity and insulin resistance: United Kingdom Congenital adrenal Hyperplasia Adult Study Executive (CaHASE). European Journal of Endocrinology/European Federation of Endocrine Societies 2013 168 887-893. (doi:10.1530/EJE-13-0128)

37 Moreira RP, Gomes LG, Mendonca BB \& Bachega TA. Impact of glucocorticoid receptor gene polymorphisms on the metabolic profile of adult patients with the classical form of 21-hydroxylase deficiency. PLoS ONE 20127 e44893. (doi:10.1371/journal.pone.0044893)

38 Falhammar H, Frisén L, Norrby C, Hirschberg AL, Almqvist C, Nordenskjöld A \& Nordenström A. Increased mortality in patients with congenital adrenal hyperplasia due to 21-hydroxylase deficiency. Journal of Clinical Endocrinology and Metabolism 201499 2715-2721. (doi:10.1210/jc.2014-2957)

Received 13 November 2014

Revised version received 11 March 2015

Accepted 6 May 2015 